\title{
Towards augmented reality for corporate training
}

\author{
B. R. Martins ${ }^{\mathrm{a}, \mathrm{b}}$, J. A. Jorge ${ }^{\mathrm{c}}$ and E. R. Zorzal ${ }^{\mathrm{a}, \mathrm{c}}$ \\ ${ }^{a}$ Instituto de Ciência e Tecnologia, Universidade Federal de São Paulo; ${ }^{\text {b}}$ Embraer S.A., \\ Brazil; ' Instituto Superior Técnico, Universidade de Lisboa, INESC-ID Lisboa, Portugal
}

\author{
ARTICLE HISTORY \\ Compiled February 19, 2021
}

\begin{abstract}
Corporate training relates to employees acquiring essential skills to operate equipment or effectively performing required tasks both competently and safely. Unlike formal education, training can be incorporated in the task workflow and performed during working hours. Increasingly, organizations adopt different technologies develop both individual skills and improve their organization. Studies indicate that Augmented Reality (AR) is quickly becoming an effective technology for training programs. This systematic literature review (SLR) aims to screen works published on AR for corporate training. We describe AR training applications, discuss current challenges, literature gaps, opportunities, and tendencies of corporate AR solutions. We structured a protocol to define keywords, semantics of research, and databases used as sources of this SLR. From a primary analysis, we considered 1952 articles in the review for qualitative synthesis. We selected 60 among the selected articles for this study. The survey shows a large number of $41.7 \%$ of applications focused on automotive and medical training. Additionally, 20\% of selected publications use a camera-display with a tablet device, while $40 \%$ refer to head-mounted-displays, and many surveyed approaches (45\%) adopt marker-based tracking. Results indicate that publications on AR for corporate training increased significantly in recent years. AR has been used in many areas, exhibiting high quality and provides viable approaches to On-The-Job training. Finally, we discuss future research issues related to increase relevance regarding AR for corporate training.
\end{abstract}

\section{KEYWORDS}

augmented reality; mixed reality; corporate training; on-the-job training; systematic literature review

\section{Introduction}

Manufacturing companies face serious challenges related to ever-changing demands by customers and suppliers alike. New technological changes and suggested interventions aim to exploit the economic potential resulting from rapidly advancing information and communication technology in the industry. Training the workforce is not a onetime issue to be addressed. Instead, it is an ongoing effort that must be nurtured and integrated into the corporate culture.

Indeed, it must continuously be on the managers' table. Certainly, on-the-job training has the potential to both improve worker productivity and save resources. Today we witness what could be the dawn of the fourth industrial revolution coming on the

CONTACT E. R. Zorzal. Email: ezorzal@unifesp.br 
heels of information technologies (IT). This revolution is characterised by Internet technologies becoming pervasive. Indeed, IT is becoming easier to use and permeate our everyday lives via intelligent components, robots, the internet of things (IoT), and interactive technologies.

These developments lie at the core of emerging smart factories where physical and digital systems become integrated to enable both mass customisation and faster product development (Demartini et al. 2017). Also, industries are investing in new technologies to improve complex processes (Blanco-Novoa et al., 2018). According to Cardoso et al. de Souza Cardoso et al. (2020), Augmented Reality (AR) is one of the leading technologies in this context. This AR lead happens because it can be applied in different industrial environments to improve process flexibility, providing information to manufacturing, improving product inspection, and providing more efficient logistics while supporting maintenance process monitoring.

$\mathrm{AR}$ is currently used in many different niche applications and diverse goals such as emulating critical situations with low human risks, creating promising opportunities to train medical professionals in a safe environment, providing general academic resources, serving as maintenance facilitator devices, in the manufacturing industries such as automotive and aeronautical as well.

$\mathrm{AR}$ is known as a technology that allows computer-generated virtual imagery to overlay physical objects in real-time accurately (Zhou et al., 2015). In AR most visual sensations and sensory stimuli come from the real world, and the virtual elements contribute less, the virtual object is set as if it were part of the real world. In Virtual Reality (VR), most sensory information is computer-generated where the virtual environment is presented as if the user were part of it.

AR applications are becoming even more affordable, thanks to more powerful hardware, including processors, head-mounted-displays (HMD) and smaller form-factors such as smartphones. Thanks to these progresses and even more sophisticated user interfaces AR is mounting to new levels of usability (Wanderley et al., 2006).

$\mathrm{AR}$, as an interaction paradigm, is predicted to be one of the enabling technologies that will power the transformation supported by the Industry 4.0 initiative (Davies, 2015), which is expected to revolutionise the current production systems. Indeed, AR is welcome in manufacturing (Damiani et al., 2018) as it can help humans to:

(1) Speed up reconfiguration of production lines;

(2) Support shop-floor operations;

(3) Implement virtual training for assembling parts;

(4) Manage the warehouse efficiently;

(5) Support advanced diagnostics integrated into modules with the working environment (Damiani et al., 2015).

This SLR focuses on the topic: Implementing virtual training for assembling parts. It is not circumscribed to industry settings but also delves on the medical, service, military and many other corporate training applications. Our goal is to elaborate a comprehensive SLR on AR as a training paradigm focused providing just-in-time RentroiaBonito et al. (2005) instructions to people so that they can perform activities more efficiently with minimum supervision from senior staff and with online assessment so as to become a reliable foundation for On-the-Job Training (OJT).

In the context of this survey we look for training suites with the potential to be used for OJT. This requires both the ability to update pedagogical content on short notice and, more importantly, to integrate the module in the actual task workflow. 
OJT makes it possible to offer spontaneous explanations or demonstrations related to a person's job responsibilities and performance requirements. Proper OJT enables people to hone their skills either by trial-and-error learning or by observing and imitating the behaviours of others (Jacobs and Osman-Gani, 1999). Although not all the studies selected in this survey target OJT, all show potential to be used in that context.

As both service providers and manufacturing systems switch from mass production to mass customisation (Burger et al., 2017), this leads to more client-specific, tailormade products and services delivered to an even diverse and larger customer base. This requires even more skilled workers to perform many different tasks in widely diverse contexts to meet market requirements. The human workforce is integrated with the manufacturing systems, and people too need to be flexible and adaptive (Yew et al., 2016). AR technology, as highlighted in this paper, provides remarkable tools and features to support the needs of this new workforce, by leveraging on and enhancing the human cognitive abilities towards augmenting their abilities and productivity.

In this paper, we survey studies related to corporate training, including training programs provided by organisations to empower the workforce to meet client expectations and to contribute to both the profitability and the mission of the company.

AR technologies are scrutinised to identify the main benefits as measured due to their application. Furthermore, we try and expose the disadvantages noted by authors. Moreover, to verify the current trend regarding the number of articles published, and check on business acceptance of AR for training purposes, we classify surveyed articles regarding AR configurations, quality of results, tracking methods used and the display hardware employed in experiments.

\section{Methodology}

The first step when conducting a systematic literature review is to define the research objectives and circumscribe the problem being addressed (Tenório et al., 2016). This systematic literature review assesses AR as used to promote work performance. This paper aims to answer the following research questions:

(1) Is AR attracting more interest to be used as a corporate training recently?

(2) What are the main challenges to adopting AR in OJT?

(3) What are the main benefits achieved by AR in OJT?

(4) Is AR a potencial tool to be used for OJT?

Before starting the systematic study we need to define a search strategy for primary publications, documenting empirical studies germane to our questions (Kitchenham and Charters, 2007).

We adopted a two-stage strategy: first we defined the keywords and the semantics of research and then we selected which digital libraries, journals, and conferences to search for studies considering the following factors:

- Availability of articles in bibliographic databases;

- Search availability from keywords to define a search string

- Relevance of bibliographic database (Kitchenham and Charters, 2007, Tenório et al. 2016).

To define the search strings to be explored, the authors discussed and agreed on (1) specifying a keyword string and (2) analyse, observe and evaluate the search results 
from the same databases for both its relevance and its representativeness.

Based on the possible results and to structure the systematic review, the selected string should feature a sufficiently large corpus of articles and their content should make it possible to answer the proposed research questions. After discussing the possible results within the authors and theirs limitations, the selected result string includes all articles and journals that feature the words (("AUGMENTED REALITY") OR ("MIXED REALITY")) AND (TRAINING) as keywords or in their titles. We chose five different databases, considering the previously discussed criteria: ACM Digital Library, IEEE Xplore, Elsevier (Science Direct), Elsevier Scopus, and SpringerLink.

Aiming to improve the results, we defined different selection criteria (inclusion, exclusion, and quality) based on the research question, String search and bibliographical databases. Our objective was to identify primary papers that would provide direct evidence about the research questions, also to reduce the likelihood of bias (Kitchenham and Charters, 2007). Specifically, we used the guidelines for performing systematic literature reviews in software engineering (Kitchenham and Charters, 2007) and PRISMA (Preferred Reporting Items for Systematic Reviews and Meta-Analyses) (Liberati et al., 2009; Moher et al., 2010) as a methodological foundation for the selection, evaluation, and exclusion phases.

As a means to facilitate this understanding, we summarise our findings in Table 1 . We read the paper titles to reduce article count. After ward, we evaluated the abstracts for each initially retained article. Last, we read the introduction and conclusions of each paper. After applying these filters, we read the remaining papers integrally. To assess the quality of the finally chosen articles, we used ten criteria which we present in Table 2. We describe them succinctly below:

RAT Is there a rationale and discussion on the assumptions upon which the study was based? Does the study feature a specific goal to be achieved in the AR scenario? (Tenório et al., 2016)

LL Are the study conclusions grounded on empirical research or does it feature a "lessons learned" report based on expert opinion? (Tenório et al., 2016)

OBJ Is there a clear statement of the goals of the research? This is important to ascertain to what extent they were met (Tenório et al., 2016)

MAT Are the materials and research methods clearly described? A clear and detailed description would make it easier to better assess and reproduce the study results.

CTXT Is there an adequate description of the context (such as industry, laboratory setting, and products used) in which the research was carried out? Again, a clear description of context would support third party verification and reproduction of the study.

EMP Was the study empirically evaluated and its results quantified? An empirical evaluation would strengthen the conclusions of a given study.

DISC Is there a discussion about the results of the study and its impacts? A clear and reasoned argument on the validity and generalisability of the conclusions significantly adds to the contribution of the report.

LIM Are the limitations of this study explicitly discussed? Such a discussion provides greater insights on the follow-up research and greatly adds to the contribution of the study as reported (Tenório et al. 2016).

OUTC Does the research also add value to the industrial community? Does the paper conclusions apply to, or identify process improvements? Can these be extrapolated beyond the original scope?

AR Are the display and tracking techniques clearly described? A clear description 
Table 1. Summary of inclusion and exclusion criteria.

\begin{tabular}{ll}
\hline Inclusion & Exclusion \\
\hline Features a training scope based on a tool that uses AR & Academic training \\
as its main characteristic & Presents less than 5 pages \\
Published from January 2014 to August 2020 & Duplicated articles \\
English is the primary language & Augmented virtuality training focused \\
Full articles & \\
\hline
\end{tabular}

allows for better contextualisation and assessment of outcomes.

Each paper received one point for each criterion duly addressed. During this reading, we collected data to provide the information needed for this classification. Furthermore, we only retained articles that scored a five minimum point grade for this SLR.

We searched each of the databases separately seeking articles from January 2014 to August 2020 that would match our seed terms. We thus collected 1952 candidate publications, including duplicates. It is important to note that we restricted our search to manuscripts written in English. Articles written in other languages did not contribute to those initial 1952 texts.

We removed 85 duplicate articles, reducing the total number to 1867. After that, all the scanning through titles and keywords have been done, and then articles identified as irrelevant ones were excluded. This step was performed by one of us and doublechecked by another to avoid biased information or any misinterpretation trimming the total candidate texts from 1867 to 310 .

At least one author read the abstract and classified each of the the remaining essays. This classification and any doubts that arose were discussed within the group. We excluded pieces not compliant with the scope of work, reducing the SLR to 180 entries.

From this point on, we retrieved each complete paper from the corpus and one of us read both its introduction and conclusions to eliminate non-relevant studies. The reader shared the classifications and we discussed possible doubts reducing the corpus to 60 papers. Figure 1 depicts the selection process.

Finally, the remaining 60 papers were read in their entirety by two authors. We retrieved the data assessing the quality of the 60 selected publications to verify and illustrate their relevance according to the selected parameters. Any doubts or disagreements were shared within the group to guarantee consistency in the final information. The parameters identified and a summary of studies included in the SLR are presented in Table 2. As the papers were read, all the relevant information was registered, in order to fulfil this systematic review goal and to structure the data to be analysed.

\section{Results and Discussion}

After reading and analysing each of the remaining 60 papers, we extracted and translated the data into information in a process guided by answer based on the research questionnaires described previously. This will be detailed in the following subsections. Figure 2(a) shows for each paper its country of origin. Notably, only twelve papers come from outside Europe or North America. USA and Italy are responsible for 15 manuscripts. European researchers alone produced 34 studies as can be seen on Figure 2(b). This analysis is relevant to identify the locations of research centres focusing on AR for corporate training. Thus, it becomes easier to highlight regions where AR in corporate training is most relevant. Therefore, we can conclude that developed coun- 


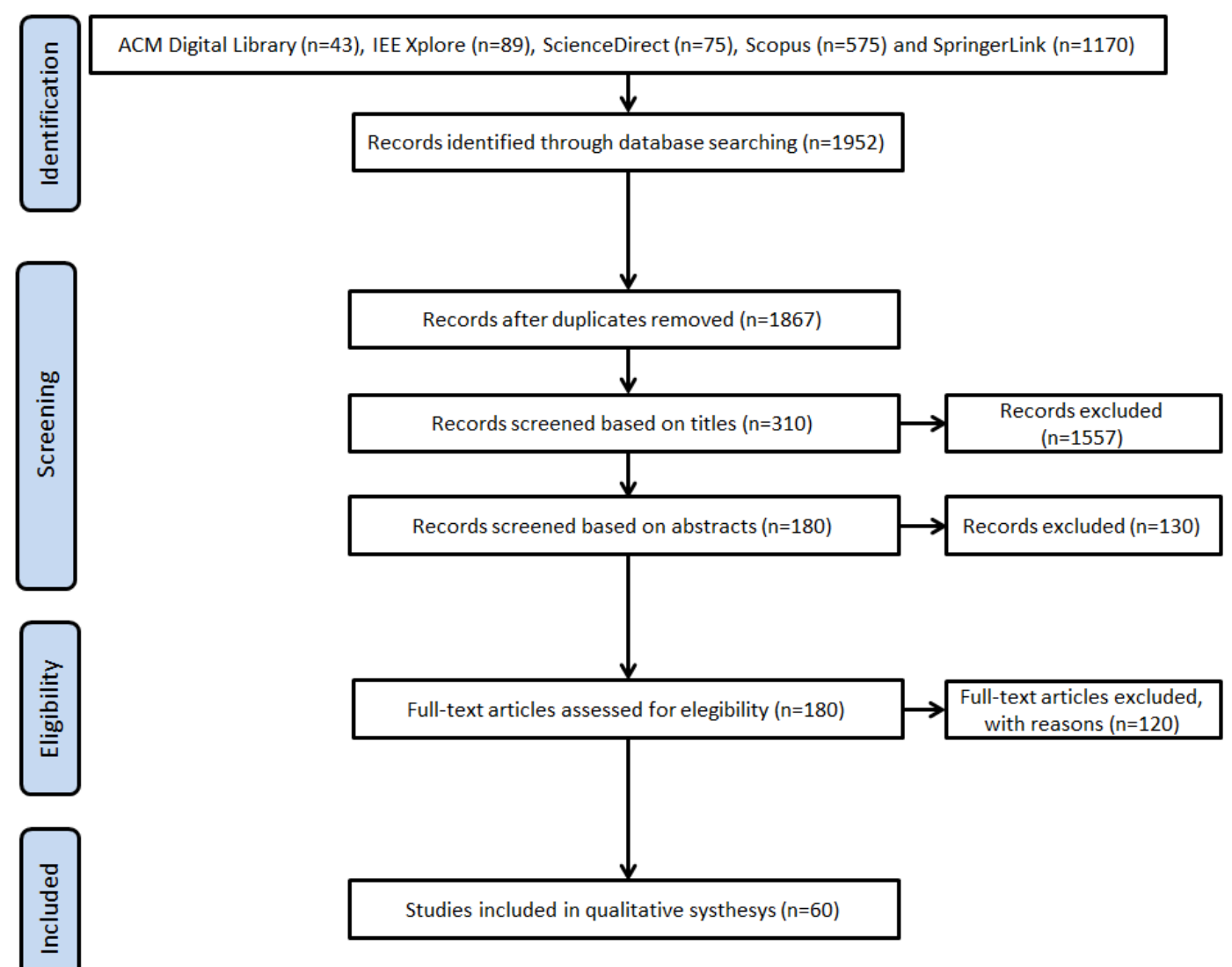

Figure 1. PRISMA flow diagram: study selection process.

tries contribute a larger share than developing countries, suggesting that investments to perform AR research are more prone to be made in locations with more resources and more educated workers.

Figure 3 identifies industries where AR is applied. Indeed, the automotive industry has the potential to become the principal application for AR training in manufacturing environments, featuring 11 papers. Another issue of note is that AR applications supporting blended learning for medical training have garnered both public and scientific interest as they are the subject of 13 publications. The remaining studies are distributed more evenly among diverse economic sectors.

Figure 4 shows display configurations used in research as well as the tracking methods applied. As we can see, HMDs are most commonly used, as they free both hands to execute required tasks during the training activities. A tablet is the second most used display both due its flexibility and its low cost. Finally, projectors and monitors make for a smaller share of display technologies. Although the use of HMD leads the applications, the sum of non-immersive displays is superior than immersive ones Further analysis of display technologies can be found later in this section.

Marker-based tracking methods are seemingly the most popular. Indeed, markerbased tracking is a well-established mechanism in AR (Schmalstieg et al., 2011) and its popularity may be due to the reduced cost (Pinto et al. 2008) besides that cameras can detect fiducial markers in real time with no difficulty (Pfeiffer and Renner, 2014).

Although 12 publications do not clearly describe the tracking method adopted, the 
Table 2. Summary of studies included in the SLR and the parameters used.

\begin{tabular}{|c|c|c|c|c|c|c|c|c|c|c|c|}
\hline Reference & RAT & LL & OBJ & MAT & CTXT & EMP & DISC & LIM & OUTC & $\mathrm{AR}$ & Score \\
\hline \begin{tabular}{l|l|} 
Wright et al. 2017) \\
\end{tabular} & + & + & + & + & + & + & + & + & & + & 9 \\
\hline Martino et al. 2017 & + & + & + & + & + & + & + & & + & + & 9 \\
\hline (Rogado et al. 2017$)$ & + & + & + & + & + & + & + & + & + & + & 10 \\
\hline (Torres-Jiménez et al. 2018) & + & + & + & + & + & + & + & & & + & 8 \\
\hline$($ Pena-kios et al. 2018$)$ & + & + & & + & + & + & + & + & & + & 8 \\
\hline (Abharı et al. 2014$)$ & + & + & + & + & + & & + & + & & + & 8 \\
\hline Li et al. 2018$)$ & + & + & + & + & + & + & + & & & & 7 \\
\hline (Hou et al. 2017 ) & + & + & + & + & + & + & + & + & + & + & 10 \\
\hline (Ramirez et al. 2015) & + & + & + & + & + & + & + & + & + & + & 10 \\
\hline (U11o et al. 2019$)$ & + & + & + & + & + & & & + & + & & 7 \\
\hline (Mendoza et al. 2015) & + & + & + & + & + & + & + & & + & & 8 \\
\hline (Mourtzis et al. 2018$)$ & + & + & + & + & + & + & + & + & + & + & 10 \\
\hline (Horejsi 2015$)$ & + & + & + & + & + & + & + & + & + & + & 10 \\
\hline Jetter et al. 2018) & + & + & + & + & + & + & + & + & + & & 9 \\
\hline (Syberfeldt et al. 2016) & + & + & + & + & + & + & + & + & + & + & 10 \\
\hline Borsc1 et al. 2015 & + & & + & + & + & + & + & + & & & 7 \\
\hline (Quandt et al. 2018) & + & + & + & + & + & & + & + & + & + & 9 \\
\hline Aebersold et al. 2018) & + & + & + & + & + & + & + & + & & & 8 \\
\hline Perdikakis et a1. 2015) & + & + & + & + & + & + & + & + & & + & 9 \\
\hline Segovia et al. 2015) & + & + & + & & + & + & + & & + & & 7 \\
\hline (Sorkoa and Brunnhofera 2019) & + & + & + & & + & & + & & & & 5 \\
\hline (Longo et al. 2017$)$ & + & + & + & + & + & + & + & + & + & & 9 \\
\hline Tatic and Tesic 2017) & + & + & + & + & + & & & & & + & 6 \\
\hline (Barsom et al. 2016) & + & & + & & + & & + & + & & & 5 \\
\hline Sebillo et al. 2016 & + & & + & + & + & & + & + & & + & 7 \\
\hline (Westerfield et al. 2015) & + & + & + & + & + & + & + & + & + & + & 10 \\
\hline Uva et al. 2018 & + & + & + & + & + & + & + & + & + & + & 10 \\
\hline (Dosh1 et al. $2017 \mathrm{a})$ & + & + & + & + & + & + & + & & + & + & 9 \\
\hline (Piedimonte and Ullo 2018) & + & + & + & & + & & + & + & & & 6 \\
\hline Lee 2019) & + & + & + & + & + & + & + & + & + & + & 10 \\
\hline Wang et al. 2018 & + & & + & & + & & + & & & + & 5 \\
\hline Stetan et al. 2018) & + & + & + & + & + & + & + & + & & & 8 \\
\hline (Bacca et al. 2018$)$ & + & + & + & + & + & + & + & + & & + & 9 \\
\hline (Kobayashl et al. 2018) & + & + & + & & + & & + & + & + & + & 8 \\
\hline (Limbu et al. 2018 ) & + & + & + & + & + & + & + & + & + & + & 10 \\
\hline (Stone et al. 2017) & + & + & + & + & + & & + & + & & + & 8 \\
\hline ( Rochlen et al. 2017 ) & + & + & + & + & + & + & + & + & & + & 9 \\
\hline (Okazaki and Takaseki 2017) & + & + & + & + & + & + & + & + & + & + & 10 \\
\hline (Mitsuhara et al. 2017 ) & + & + & + & + & + & + & + & + & & + & 9 \\
\hline Tamaazoustı et al. 2016 & + & + & + & & + & & + & + & + & + & 8 \\
\hline$($ Herron 2016$)$ & + & & + & & + & & + & + & & & 5 \\
\hline Wang et al. 2016 & + & + & + & & + & + & + & + & + & & 8 \\
\hline Bifulco et al. 2014) & + & + & + & + & + & + & + & + & & + & 9 \\
\hline (Leitritz et al. 2014 ) & + & + & + & + & + & + & + & + & & + & 9 \\
\hline Kwon and Kim 2019) & + & + & + & + & + & + & + & & & + & 8 \\
\hline Yang et al. 2019) & + & + & + & + & + & + & + & + & + & + & 10 \\
\hline Buttner et al. 2020 & + & + & + & + & & + & + & + & + & + & 9 \\
\hline Koo et al. 2019 & + & + & + & + & + & + & + & + & & + & 9 \\
\hline Ferrati et al. 2019 & + & + & + & + & + & + & + & + & + & + & 10 \\
\hline van Lopik et al. 2020 & + & + & + & + & + & + & + & + & + & + & 10 \\
\hline (Catal et al. 2019) & + & + & + & + & & + & + & + & + & + & 9 \\
\hline (Ballan et al. 2019 ) & + & + & + & + & + & + & + & + & & + & 9 \\
\hline Wang et al. 2020 & + & + & + & + & + & + & + & + & + & + & 10 \\
\hline Boonbrahm et al. 2019) & + & + & + & + & + & + & + & & & + & 8 \\
\hline P1lati et al. 2020 & + & + & + & + & & + & + & + & + & + & 9 \\
\hline Aziz et al. 2020 & + & + & + & + & + & + & + & & + & + & 9 \\
\hline (Eder et al. 2020) & + & + & + & + & + & + & + & + & + & + & 10 \\
\hline Koutitas et al. 2020 & + & + & + & + & + & + & + & + & & + & 9 \\
\hline (Romero et al. 2019$)$ & + & + & + & + & & + & + & + & + & + & 9 \\
\hline (Gabajová et al. 2019) & + & + & + & + & & + & + & & + & + & 8 \\
\hline
\end{tabular}

data are still valid to list $3 \mathrm{D}$ recognition in second place, with an increasing trend for the near future. 15 papers feature a more computationally demanding technology, markerless tracking, that combines 2D and 3D recognition Sensor-based approaches are less popular and include electromagnetic and inertial tracking.

The following subsections discuss the four Research Questions (RQ) in detail, discussing the relevant findings in the surveyed literature. 


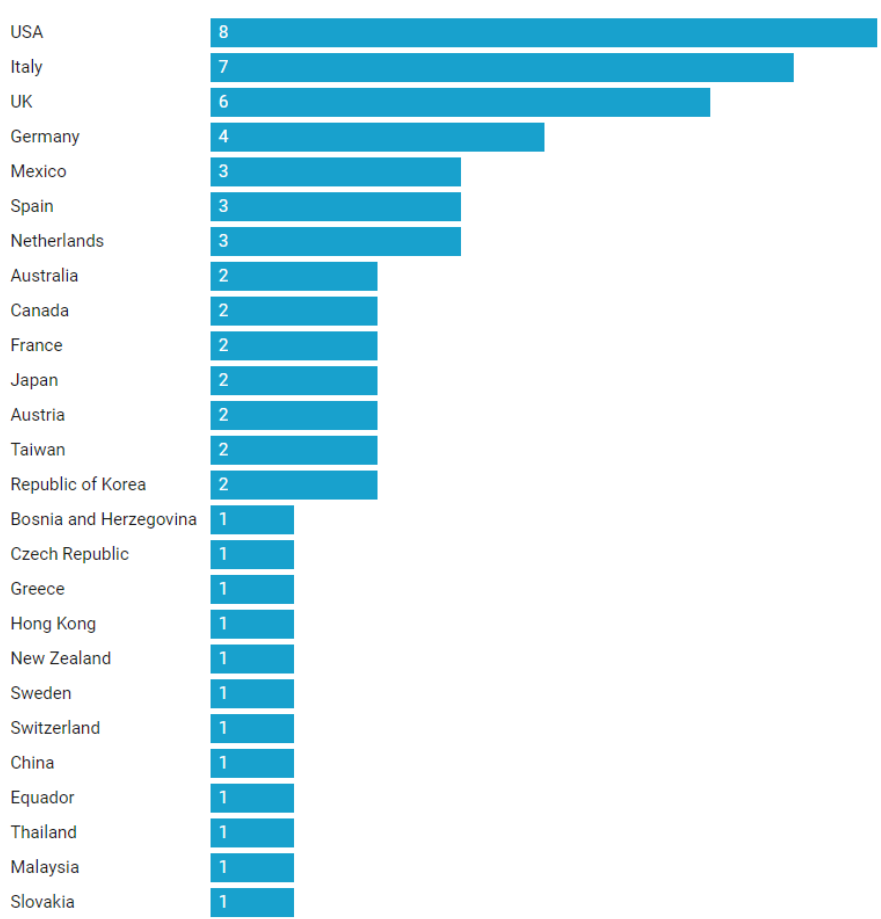

(a) Final publication distribution by country.

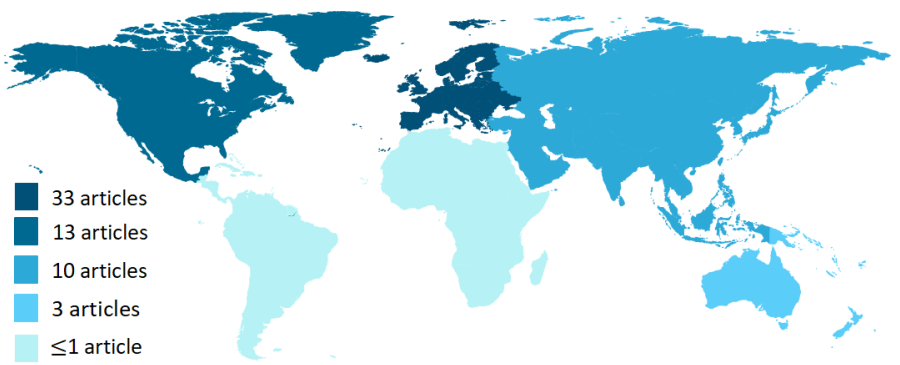

(b) Final publication distribution by continent.

Figure 2. Final publication distribution by continent and by country.

\subsection{RQ1 - Is AR attracting more interest to be used as a corporate training recently?}

As it is observed in Figure 5, there is a steady increase in publications on corporate training over the past few years. Indeed, from the initial year considered in this SLR until the entire last year, their number has grown significantly. Also worth noting, the number of publications featuring AR and training in either their title or keywords has steadily increased over the years, illustrating a growing interest of the scientific community.

Putting into perspective, the percentage of studies regarding corporate training has been stable from $2.43 \%$ to $1,75 \%$ in recent year, following the increasing trend in the AR articles published. While in 2014 the selection rate was $2 / 82$, in 2019 this number reached 13/737. Thus AR is increasing as the main tool in training, both causing and reflecting the growing number of publications studying its effectiveness. Thus we can answer positively Research Question 1: Is AR attracting more interest to be used as a corporate training recently. Moreover, training is a growing area of application 


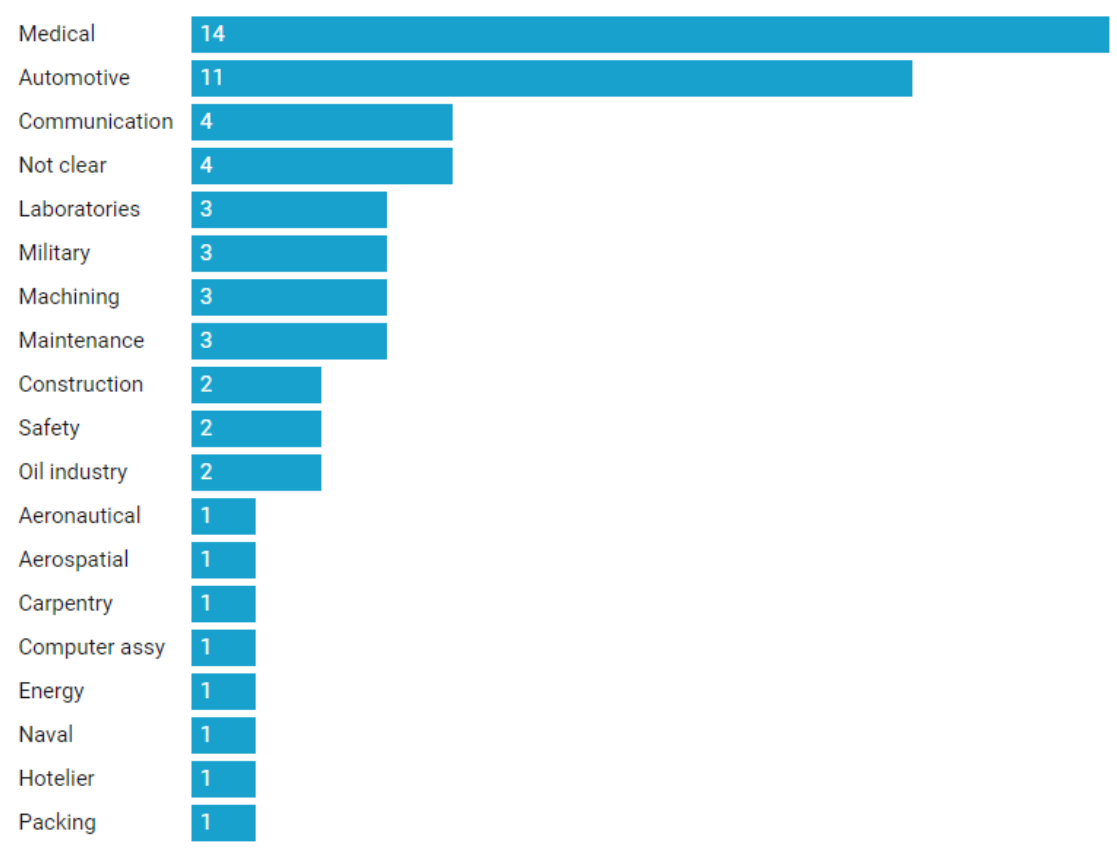

Figure 3. Final area distribution.

for AR, taking into account the share of training related papers among AR scientific publications.

\subsection{RQ2 - What are the main challenges to AR in OJT?}

Only 16 of the selected articles do not address difficulties in developing training applications. On the other hand, the remaining 60 , identify at least one challenge. In general, the following issues have been reported on using AR as a training tool: adapting nontech savvy users to AR technology (Wright et al., 2017), training engagement (Rogado et al., 2017), field of vision (Wang et al., 2018), visual occlusion limitations (Herron, 2016), ergonomics (Stone et al., 2017), environment interference (Bifulco et al., 2014), dependence on internet connection (Ullo et al., 2019), dependence on batteries, fear of changes (Pena-Rios et al., 2018), handling perspective and depth (Abhari et al., 2014), management engagement (Li et al., 2018), high cost of customization (Longo et al., 2017), synchronizing reality and virtuality (Hou et al., 2017), choosing the training scope (Ramírez et al., 2015), resource costs when updating AR training content (Ullo et al. 2019), acquiring trainers for interpersonal interaction (Mourtzis et al., 2018), camera focus (Hořejší, 2015), software issues (Ullo et al., 2019) and ergonomic issues of wearables when used continuously (Jetter et al., 2018).

Training people non-familiar with the technology was a challenge identified in eight of the studies including Perdikakis et al. (2015). Since AR training systems commonly use software and require minimum digital expertise, people experiencing difficulties with IT are either prone to reject AR, be too ashamed to ask for help, or do not engage in the experience (Wright et al., 2017). The interest in and value perception of AR technologies are likely to be higher for both students and technology-savvy people and may also vary according to gender (Habig, 2019).

Another issue regarding engagement is percentage of studies that highlighted either 


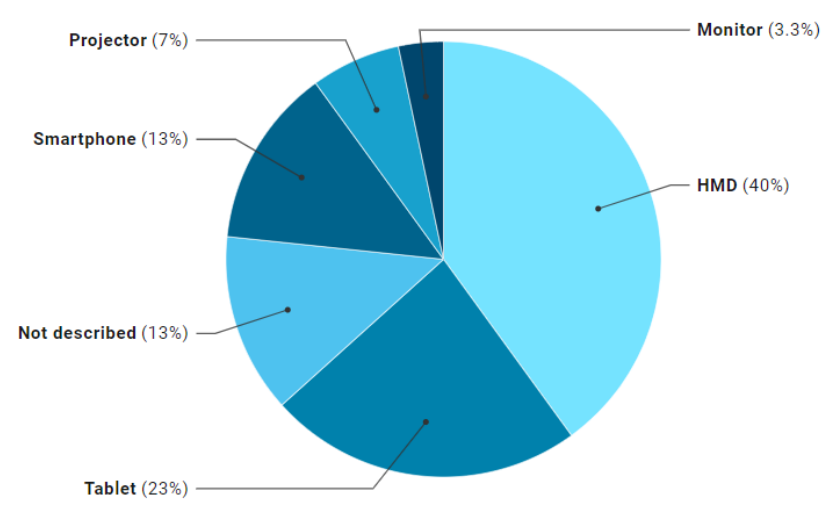

(a) Final display classification.

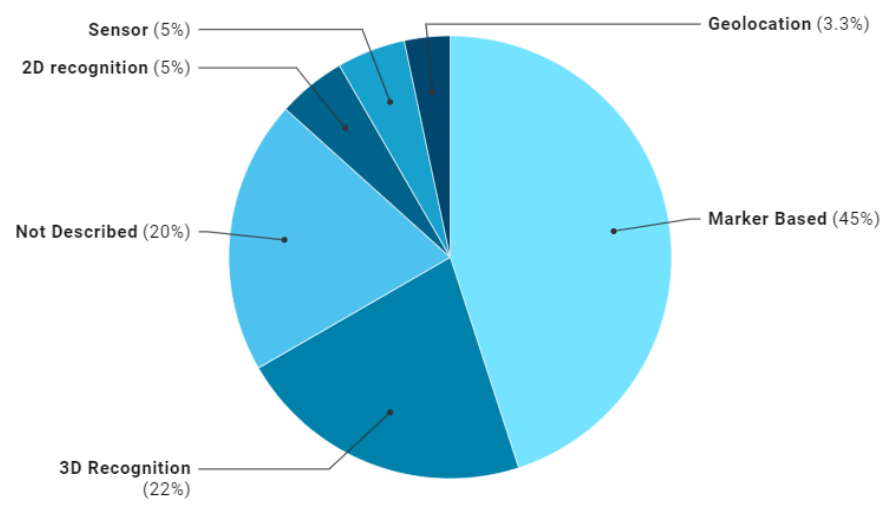

(b) Final tracking method classification.

Figure 4. Final display and tracking method classification.

low enthusiasm or a low perception of benefits by trainers. Indeed, $8.3 \%$ of the studies discussed this finding. Notably, several studies indicate that either the managers and the corporate directors actively support and endorse the new training technology or the trainers/operators will tend to reject it.

Another aspect covered by the analysis is the hardware required. Displays, if not chosen carefully, can pose significant obstacles to training. In effect, 12 studies mentioned troubles with the displays selected including Herron (2016). The problems either related to the wrong choice of display (ex: instead of using a handheld display, a wearable would fit the function better) or troubles pertaining to the hardware proper, or reported discomfort with wearable devices during continued use.

Other issues mentioned in the literature include display price point. Since many expensive displays are exclusively used for specialised niche training applications, they might not be cost-effective.

Ten studies reported issues affecting AR markers. Both complexity of marker technology and interference from the environment are the leading causes of problems reported in Westerfield et al. (2015). Placing markers in corners or in open environments can cause misreadings (Bifulco et al., 2014). Also, the cost and the environmental constraints cameras to establish reliable tracking were also discussed. On the other hand, software can also be a source of complications. Eleven studies mentioned the software presenting at least one problem, as discussed by Hořejší (2015). In this case, the main issue was due to inflexible configurations or applications designed for on rails exe- 


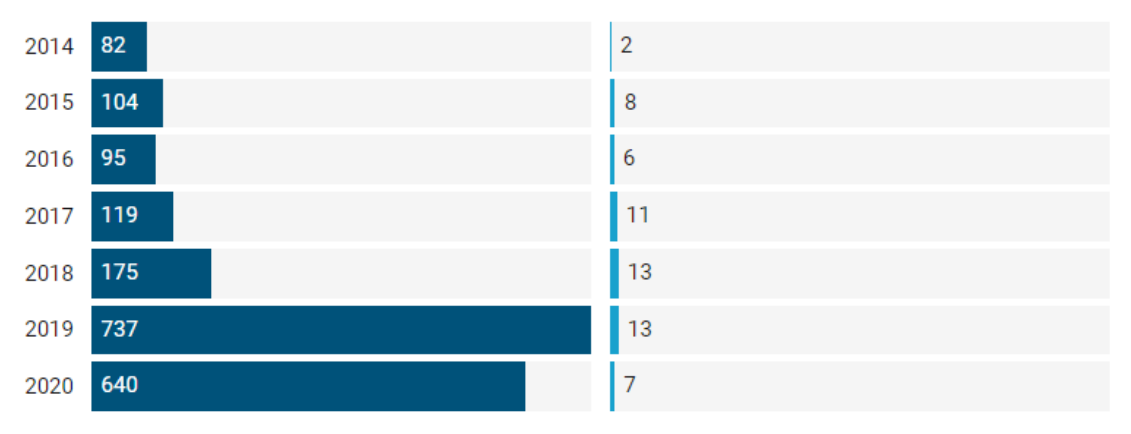

Figure 5. Final publication year distribution.

cution and not being able to handle unusual conditions or inputs in a graceful way. Other problems reported off-the-shelf software lacking customisation for AR, such as video calling applications. Customisation was pointed out as a strong feature in 18 articles e.g. (Torres-Jiménez et al., 2018) given the added flexibility. However, eight papers identify room for improvement as seen in the Longo et al. (2017). Customising software can be difficult mainly due to the deep knowledge required to edit the training software, or the preparation need to change training sequences or dialogues. Even though when inside a training session it may be possible to insert additional information or change feedback triggered from markers relatively easy and cheap, changing the business logic of the training software or physically moving tracking devices for a different training module, can be much harder and expensive.

Internet access is flagged as an issue in two studies (Pena-Rios et al., 2018; Ullo et al., 2019), mainly due to unstable connections, or insufficient bandwidth as AR requires video streaming when deployed remotely, or when it requires external processing.

The 3D perception and perspective are mentioned as challenges by 14 studies namely Kobayashi et al. (2018). Properly matching virtual content with real settings to meet training requirements is essential to avoiding perception troubles. Simulator (3D) sickness (Lee, 2019) needs to be avoided, as the distortion between real objects and virtual content minimises breaks in the flow of work and increases the trainee's attention to the instructional content.

Table 3 synthesises the main points extracted during our survey regarding challenges to the adoption of AR. We also describe them succinctly below:

LELP Low enthusiasm or a low perception of benefits by trainers; in many contexts this may mean scepticism towards unproven technologies or a steep learning curve characteristic of some early systems;

EIFC Engagement issues or fear of changes; Indeed in many corporate environments, introducing a new technology can be met with resistance by people who perceive their job security being threatened;

3DP 3D perception regarding the perspective and deepness; These maybe related to display quality, registrationb problems or both;

HWI Hardware issues; Some of the early hardware could be quirky and prone to failure;

DMR Difficulties regarding the marker readings; These might either be caused by poor illumination or unfortunate choice of surfaces;

DBC Difficulties with broadband connection and data transfer; Perceived lag can cause simulator sickness, poor registration or even missing key animations; network latency can exacerbate these issues; 
CI Customisation issues; As AR training environments can be complex, budgetary issues can lead to under-featured poorly adapted software;

SOFT Software issues; Bugs or poorly documented features can lead to unanticipated behavior;

TPNF Training people non-familiar with the technology; Some more complex systems may have a steep learning curve, which prevents non-specialised people to take full advantage of AR for training of job-specific tasks;

NDNC Not described or not clear.

\subsection{RQ3 - What are the main benefits achieved by AR in OJT?}

From examining the 60 articles we conclude that AR, although with different descriptions, provides the following advantages: reduced training costs (Ullo et al., 2019), facilitated customization (Uva et al., 2018), raised effectiveness (Doshi et al., 2017b), low-risk when exercising critical safety issues (Rogado et al., 2017), attractive to specific groups (Wright et al., 2017), flexible information display (Pena-Rios et al., 2018), improved worker confidence (Torres-Jiménez et al., 2018), fast access to information (Sebillo et al., 2016), support to decision-making (Kobayashi et al., 2018), improved skill transfer process (Pena-Rios et al., 2018), real-time interaction (Sebillo et al. 2016), empowering operators (Syberfeldt et al., 2016), displaying immersive environments (Li et al., 2018), familiarisation with the work routine (Abhari et al., 2014), allowing non-specialised staff to perform specific tasks (Ullo et al., 2019), manpower savings (Hou et al. 2017), decreased training time (Wang et al., 2016), decreased perceived distances (Hou et al., 2017), decreased error rates (Leitritz et al., 2014), reduced cognitive workload (Okazaki and Takaseki, 2017), easy to store and transport (Perdikakis et al., 2015), decreased set-up time (Quandt et al., 2018), welcome by users (Mitsuhara et al., 2017), increased motivation (Bacca et al., 2018), friendly remote assistance and better long term retention of information (Kobayashi et al., 2018) among others. In this subsection, we will discuss how the previously mentioned benefits are documented throughout the articles and analyse how these affect the perceived suitability of AR to training in the working environment. Although 15 articles presented at least a quantified benefit, 59 mentioned qualitatively perceived or immeasurable gains.

Tallying the information from (Ferrati et al., 2019; Hořejší, 2015; Koutitas et al., 2020; Lee, 2019; Longo et al., 2017; Mourtzis et al., 2018; Ramírez et al., 2015; Uva et al., 2018; Westerfield et al. 2015) time savings with respect to traditional approaches average $28.48 \%$ (considering only the final number provided in the respective paper). An additional 27 articles mentioned unquantified gains related to time spent as compared to traditional methods. The main issue regarding time measurements is that the training suite can advance stages as the operator progresses, as all modules are geared to individual learning and the information presented is focused, in order to narrow attention to the training goals. Another characteristic observed is that training modules can use display resources to provide unsolicited information at any moment. Effectively, there is no need to wait for human-generated events to happen, as the simulation can evolve in real time. Another key benefit highlighted by studies is the perceived lower error rate during task execution when using AR. In effect, Balian et al. (2019); Doshi et al. (2017b); Ferrati et al. (2019); Koutitas et al. (2020); Leitritz et al. (2014); Mourtzis et al. (2018); Uva et al. (2018) measured the operator errors to be, on 
Table 3. Summary of challenges identified in the SLR

\begin{tabular}{|c|c|c|c|c|c|c|c|c|c|c|}
\hline Reference & LELP & EIFC & $3 \mathrm{DP}$ & HWI & DMR & $\mathrm{DBC}$ & $\mathrm{CI}$ & SOFT & TPNF & NDNC \\
\hline (Wright et al. 2017) & + & & & & & & & & & \\
\hline (Martino et al. & & & & & & & & & & + \\
\hline (Rogado et al. 2017 ) & & + & & & & & & & & \\
\hline (Torres-Jimenez et al. 2018) & & & & & & & & & & + \\
\hline (Pena-Kios et al. 2018) & & + & + & + & + & + & & & & \\
\hline Abharı et al. $20 \overline{14}$ & & & + & & & & & & & \\
\hline (L1 et al. 2018$)$ & & + & & & & & & & & \\
\hline$\left(\begin{array}{l}\text { Hou et al. } 2017) \\
(\text { Ramirez et al. } 2015)\end{array}\right.$ & & & & & & & + & + & & \\
\hline $\begin{array}{l}\text { (Ramirez et al. 2015) } \\
\text { (Ullo et al. 2019) }\end{array}$ & & & & & & & + & + & & \\
\hline Miendoza et al. 2015 & & & & & & & & & & + \\
\hline 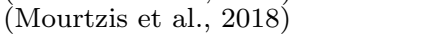 & & + & & & & & & & & \\
\hline 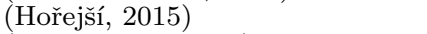 & & & & & + & & & + & & \\
\hline Jetter et ai. 2018) & + & + & + & + & & & + & & & \\
\hline Syberfeldt et al. 2016) & & & + & + & & & + & & & \\
\hline Borscl et al. 2015 & & & & & & & & & + & \\
\hline Quandt et al. 2018 & & & & & + & & & & & \\
\hline Aebersold et al. 2018) & & & & & & + & & & & \\
\hline (Perdikakis et a1. 2015) & + & & & & + & & & + & & \\
\hline (Segovia et al. 2015) & & & & & & & & & & + \\
\hline Sorkoa and Brunnhofera 2019) & & & & & & & & & & + \\
\hline (Longo et al. 2017$)$ & & & & & & & + & & & \\
\hline (Tatic and Tesic 2017) & & & & + & & & & & & \\
\hline Barsom et al. 2016 & & & & & + & & + & + & & \\
\hline Sebillo et al. 2016$)$ & + & & & & & & & & & \\
\hline Westerneld et al. 2015) & & & + & & + & & & & & \\
\hline Uva et al., 2018) & & & & & & & + & & & \\
\hline (Doshi et al. 2017a) & & & & & & & & & & + \\
\hline (P1edimonte and Uilo 2018) & & & & & & + & & + & & \\
\hline (Lee, 2019) & & & + & & & & & & & \\
\hline (Wang et al. 2018) & & & + & + & & & & & & \\
\hline (Stefan et al. 2018) & & & & & & & & & & + \\
\hline (Bacca et al. 2018$)$ & & & & & & & & & & + \\
\hline Kobayashi et al. 2018) & & & + & & & & & & & \\
\hline (Limbu et al. 2018) & & + & + & & + & & & & & \\
\hline Stone et al. 2017 & & + & + & & & & & & & \\
\hline Rochlen et al. 2017 & & & & + & & & & + & & \\
\hline Okazakı and Takaseki, 2017) & & + & & & & & & & & \\
\hline (Mitsuhara et al. 2017$)$ & & & & & & & & + & & \\
\hline (Tamaazoustı et al. 2016) & & & + & & & & & & & \\
\hline Herron 2016) & & & + & + & & & & & & \\
\hline Wang et al. 2016 & & & & & & & & & & + \\
\hline Bitulco et al. 2014 & & & + & & + & & & + & & \\
\hline (Leitritz et al. 2014 & & & & & & & & & & + \\
\hline (Kwon and Kim, 2019) & & & + & & & & & & & \\
\hline (Yang et al. 2019) & & & + & & & & & + & & \\
\hline (Buttner et al. 2020$)$ & + & & & & & & & & + & \\
\hline \begin{tabular}{|l|l|} 
Koo et al. 2019 \\
\end{tabular} & & & & & & & & & & + \\
\hline \begin{tabular}{|l|l|} 
Ferrati et al. & 2019 \\
\end{tabular} & & & & + & + & & & & & \\
\hline van Lopik et al. 2020) & + & + & & + & & & & + & + & \\
\hline Catal et al. 2019) & & & & & & & & & & + \\
\hline (Balian et al. 2019) & & & & & & & & & + & \\
\hline (Wang et al., 2020 & & & & & & & & & & + \\
\hline Boonbrahm et al. 2019) & & & & + & & & & & & \\
\hline (P1lati et al. , 2020) & & & & & & & & & & + \\
\hline Aziz et al. 2020 & & & & & & & & & & + \\
\hline (Eder et al. 2020 & & & & + & & & & & & \\
\hline Koutıtas et al. 2020 & & & & + & & & & & + & \\
\hline Romero et al. 2019 & & & & & + & & & & + & \\
\hline (Gabajova et al. 2019 & & & & + & & & & & & \\
\hline
\end{tabular}

average, about $47.85 \%$ lesser than conventional settings during the task execution. 20 articles mentioned a decrease in related mistakes in comparison with traditional methods. AR can provide specific, relevant and customised information about every step of the training, which can explain why AR-based training tends to yield less mistakes. Another corroborating characteristic is that AR presents information graphically and thus makes it easier to understand than text-based delivery.

Cost-related issues are also relevant. Besides the inherent money savings due to 
learning time reduction and decreased error rates, the costs regarding learning content production can be addressed. One study Ramírez et al. (2015) measured these to be $41 \%$ lesser as compared to traditional methods. Besides that, 25 studies mentioned, without measuring, that total cost of training was lower, namely Stone et al. (2017).

An advantage that is immeasurable at this point but worth mentioning is time savings by senior operators cited by 4 essays (Boonbrahm et al., 2019; Ferrati et al. 2019; Ullo et al. 2019; Wang et al., 2020) in the production environment who would otherwise be engaged to help and provide information to new employees.

The flexibility afforded by AR was both welcome and noticed in 19 articles, including Torres-Jiménez et al. (2018), which stated that AR makes content customisation easier. Once the main body and training methodology are defined, it becomes simpler to change environments (Sebillo et al., 2016), change the information given, or even update these in real-time depending on perceived requirements.

The possibility to simulate a given environment is quoted by 25 studies e.g. (Barsom et al., 2016). Also, improvements in safety are quoted by 7 papers e.g. (Barsom et al., 2016; Li et al., 2018; Rogado et al., 2017; Torres-Jiménez et al., 2018; Wang et al., 2020). These two characteristics are strongly related. As it becomes easier to simulate an environment, specific conditions can be simulated too (Aebersold et al., 2018). Hence it is possible to train the operator using comparatively inexpensive equipment without incurring health or safety risks in case of misguidances (Stone et al., 2017). It is possible to simulate events and manage stressful situations without incurring extra costs beyond content production. Dangerous environments or unsafe activities can also be simulated without major safety issues to the operator, as discussed in Stefan et al. (2018), it is not necessary to expose novice operators to radiation, but training is required on how to manage emergency situations in hazardous environments e.g. nuclear power plants.

The cognitive advantages of AR are discussed in 29 articles. Indeed, many operators welcome and experience positive attitudes towards AR-based learning as it requires less cognitive resources to achieve results comparable to traditional methods (Okazaki and Takaseki, 2017). A key advantage is that learning scenarios can be repeated as many times as needed without embarrassment. Since the delivery is strongly visual the scene can be placed exactly at the time and place relevant to training, avoiding possible confusion. The same situation can also be played in different ways, as a pokayoke ${ }^{1}$ to overcome any misunderstanding of the message the training is supposed to impart (Jetter et al., 2018). Table 4 synthesises the main points extracted during our literature survey regarding the main benefits outlined above. We also describe them briefly below:

RTC Reduced training cost;

ECE Easy customisation and editing;

LER Lower error rate during task execution;

LTT Lower training time;

LCL Lower cognitive load;

ARFT AR provided environment facilities for training;

SAFTI Safety improvements;

BNDNC Benefits not described or not clear.

\footnotetext{
${ }^{1}$ Poka-yoke is a Japanese term that means "mistake-proofing" or "inadvertent error prevention". A poka-yoke is any mechanism in any process that helps an equipment operator avoid (yokeru) mistakes (poka).
} 
Table 4. Summary of benefits of AR-based learning and training as identified in our literature review

\begin{tabular}{|c|c|c|c|c|c|c|c|c|}
\hline Reference & RTC & ECE & LER & LTT & LCL & ARFT & SAFTI & BNDNC \\
\hline (Wright et al., 2017) & + & + & & & & & & \\
\hline (Martino et al. 2017) & + & + & + & + & + & & & \\
\hline ( & & & & & & + & + & \\
\hline (Torres-Jimenez et al. 2018) & & + & & + & + & & + & \\
\hline (Pena-Rios et al. 2018) & + & + & & & + & & & \\
\hline Abharl et al. $20 \overline{14}$ & & & & + & + & + & & \\
\hline L1 et al., 2018) & + & & & & + & + & + & \\
\hline (Hou et al. 2017 ) & + & & & + & & + & & \\
\hline ( Ramirez et al. 2015$)$ & + & & & + & & & & \\
\hline (Ullo et al. 2019$)$ & + & & & + & & & & \\
\hline (1/lendoza et al. 2015) & + & & + & + & & & & \\
\hline (1̄ourtzis et al. 2018 & & & + & + & & & & \\
\hline 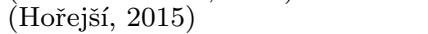 & + & + & & + & & & & \\
\hline Jetter et al. 2018) & & & + & + & + & + & & \\
\hline Syberfeidt et al. 2016 & + & + & + & + & + & & & \\
\hline Borsci et al. 2015 & & & & & & & & + \\
\hline Quandt et al. 2018) & + & + & + & + & & + & & \\
\hline Aebersold et al. 2018 & & & & + & + & + & & \\
\hline ("Perdikakis et al. 2015$)$ & + & + & & & + & + & & \\
\hline Segovia et al. 2015 & + & & & & & & & \\
\hline Sorkoa and Brunnhofera 2019 & + & & + & + & & + & & \\
\hline Longo et al. 2017) & & & & + & + & + & & \\
\hline (Tatic and Tesic 2017) & & & + & & & & & \\
\hline (Barsom et al. 2016 & & + & & & + & + & + & \\
\hline Sebillo et al. 2016$)$ & & + & & + & + & & & \\
\hline Westertield et al. 2015) & + & & & + & & & & \\
\hline (Uva et al. 2018$)$ & + & + & + & + & + & & & \\
\hline (Doshi et al. $2017 a)$ & + & & + & & & & & \\
\hline Pिiedimonte and Uillo 2018) & + & + & + & & + & & & \\
\hline (Lee, 2019) & + & & & + & + & & & \\
\hline 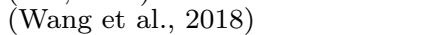 & + & & + & + & & & & \\
\hline Stefan et al. 2018 & & & + & + & & + & & \\
\hline Bacca et ai. 2018 & & & + & & + & & & \\
\hline Kobayashi et al. 2018) & & + & 1 & + & + & + & & \\
\hline (Limbu et al. 2018 ) & & + & & & + & & & \\
\hline (Stone et al. 2017 & + & & & & & + & & \\
\hline (Rochlen et al. 2017 ) & & & & & + & + & & \\
\hline (Ukazakı and Takaseki, 2017) & & & & & + & & & \\
\hline (Mitsuhara et al. 2017) & & & & & + & + & & \\
\hline (Tamaazoustı et al. 2016) & & & & & + & + & & \\
\hline ("Herron 2016$)$ & + & & + & + & & & & \\
\hline Wang et al. 2016) & + & & & + & + & + & & \\
\hline Bifulco et al. 2014 & & & & + & + & & & \\
\hline 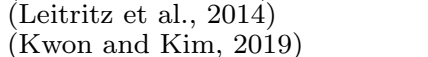 & & & + & & & & & \\
\hline Kwon and Kim 2019) & & & & & + & & & \\
\hline$\left(\begin{array}{l}\text { Yang et al. } 2019) \\
\text { Buttner et al. }\end{array}\right.$ & & & + & + & & + & + & \\
\hline $\begin{array}{l}\text { Buttner et al. } 2020 \\
\bar{\tau}\end{array}$ & & & + & & & + & & \\
\hline Koo et al. 2019 & & + & & & + & & & \\
\hline \begin{tabular}{l|} 
Ferrati et al. \\
van Lopik et al. 19 \\
val
\end{tabular} & + & & + & + & + & & & \\
\hline van Lopik et al. 2020 & & + & & & & & + & \\
\hline Catal et al. 2019 & & & & & + & + & + & \\
\hline Balian et al. 2019 & + & & + & & + & + & & \\
\hline 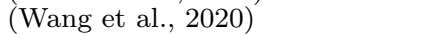 & & & & & + & & & \\
\hline Boonbrahm et al. 2019 & + & & & & + & + & & \\
\hline P1lati et al. 2020 & & & & + & & & & \\
\hline \begin{tabular}{|l|l|} 
Azız et al. & 2020 \\
Eder et al. & 2020 \\
\end{tabular} & & & & & + & & & \\
\hline$\left(\begin{array}{l}\text { Eder et al. } \\
\text { Koutitas et al. } 2020)\end{array}\right.$ & + & $\begin{array}{l}+ \\
+\end{array}$ & + & + & + & + & & \\
\hline Romero et al. 2019 & & + & & & + & & & \\
\hline (Gabajova et al., 2019) & & + & & + & + & & & \\
\hline
\end{tabular}

\subsection{RQ4 - Is AR a potential tool to be used for OJT?}

Based on the answers to the three previous research questions, it is possible to conclude AR has potential to become a useful tool for OJT in many settings. Its features and benefits seemingly mesh well with OJT requirements, and we can see that once development environments support enough flexibility (Tamaazousti et al., 2016), training suites are geared towards the workplace experience (Barsom et al., 2016), the learning experience becomes job-oriented, learning module contents can be updated with 
relative ease and training packages can be used without specialised supervision (Ullo et al., 2019). The just-in-time based e-learning can be supported by AR technology since the training modules just require the operator to be available and the training station prepared (Mendoza et al., 2015).

The advantages highlighted in the RQ3 fit well with most objectives of OJT. Indeed, 59 studies report strong benefits as exemplified by Quandt et al. (2018), and only 46 described difficulties, notably in Syberfeldt et al. (2016). Nonetheless, as far as the result we analysed, 15 of these studies could quantify productivity gains e.g. (Leitritz et al. 2014). On the other hand, none of the reported disadvantages could be precisely measured during the published experiments. While current trends show AR as being applied to individual training tasks, comprehensive OJT can be the next application to enjoy widespread AR deployment.

\subsection{Limitations of the study}

Even though the authors intended to cast as wide a net as possible, the articles reviewed in this research are limited to the journals indexed in the databases: ACM Digital Library, IEEE Xplore, Elsevier (Science Direct), Elsevier Scopus, and SpringerLink. This research is limited to experimental studies presented in article format, thus possibly missing more anecdotal or corporate proprietary evidence. Although all selected studies were integrally read, some info could be missing or misunderstood during the analysis. As the field evolves and given the rapid pace of AR development, future iterations of this study could shed more light on our findings. In addition to that, this SLR is limited to academic papers in a review intended to assess the imminent impact of a technology in the industry.

\section{Conclusion}

From the analysis of the benefits and disadvantages presented in this paper, it is clear that AR is a maturing approach to corporate training scenarios as the technology overcomes its growing pains and associated challenges. Indeed, at the current development stage, well-thought-out planning stages before training programs and learning content are deployed can maximise both skill improvement and workforce quality. This planning should include the correct evaluation of the target audience. Indeed, depending on the digital skill levels of the target audience, AR applications can be complicated and feature unnecessary layers or be straight and simple to address less sophisticated or casual audiences.

The display selection can be critical to success and should consider both the training scope, environmental, safety, and ergonomics issues. If the activity requires a hands-free operation, we recommend either an HMD or a projector-based setting. If the training is time-intensive, wearable devices can present ergonomic issues. If the budget does not include specific hardware for each worker, or if the training has to be conducted simultaneously by many trainees, it should be desirable to adopt smartphones or tablets as primary displays.

Tracking methods need attention while considering the environment. Variations in lighting can interfere with the reading of markers depending on the camera used. The surface on which to place the markers should be studied. If irregular surfaces are likely

to cause misreadings, other tracking devices such as a sensor-based or a markerless tracker could be chosen. 
The training environment should be correctly prepared to support any flow of action that the trainees shall undergo. Avoiding inflexible trainee-" on rails" experiences should improve the learning experience.

Software development should take into account the ultimate training objectives and accommodate the stakeholders mentioned above.

If developers are to heed these recommendations, they can increase the training's benefits and minimise the challenges of using AR as an OJT useful tool.

Following current trends, design thinking should contribute better results to developing AR training software. Another issue to take into account is gamificationBarata et al. (2013) as a device to optimise and to engage trainees. Moreover, just-in-time solutions can facilitate software development regarding both the game engine and training structure to decrease efforts required to develop the software and increase the application range of the training and its access to more developers.

Although the studies identified different benefits and some of them performed measurements, there is still a strong need for a comprehensive survey that combines all measurements and compares them with the traditional OJT training methods. The challenge consists of AR-based training in an industrial OJT application for the mastering of one activity, in which the following critical performance indicators shall be directly compared with traditional training programs: (1) the cost, (2) the training pace, (3) the time required, (4) the learning curve, (5) the cognitive workload, (6) the perception regarding AR and (7) the technology acceptance.

As a means to develop future work relevance, AR will increasingly use smartphones or other wearable devices to accommodate the growing adoption of AR everyday settings and improve people's familiarity with the technology. However, AR can still evolve in fundamental ways to improve both the user and learning experiences. Further Artificial Intelligence developments can make for more natural and sophisticated dialogues and better coaching of trainees to identify possible pitfalls and proactively suggest better ways to accomplish tasks. Further advances in HMDs and wearable devices will surely make AR applications usable for extended periods, a typical worker complaint since the inception of the field. Finally, ever more advanced user interface techniques, coupled with more natural interaction modalities going beyond speech and gestures, should make for ever more natural user experiences, increasing worker engagement, and productivity of AR-based learning environments.

\section{Acknowledgements}

The last author would like to thank the São Paulo Research Foundation (FAPESP) for support of this research: grant\#2018/20358-0, FAPESP.

This work was partially supported by Portuguese government national funds through FCT, Fundação para a Ciência e a Tecnologia, under project UIDB/50021/2020.

\section{Notes on contributors}

Bruno R. Martins is a student at the Professional Master in Technological Innovation, Federal University of Sao Paulo, where he is researching about the augmented reality applications on training. He is graduated in industrial engineering and simultaneously works as an engineer at EMBRAER S.A on the manufacturing system. His main 
research interests are Virtual Reality, Augmented Reality and On-The-Job Training.

Joaquim A. Jorge is a full professor of computer graphics and multimedia at the Department of Computer Science and Engineering of the IST, University of Lisbon, Portugal, and scientific coordinator of the Research Group on Visualisation and Multimodal Interfaces of the Institute for Computer and Systems Engineering - INESC-ID. Since 2007 he is editor in chief of Computers \& Graphics Journal and serves or has served on the board for six other international journals.

Ezequiel R. Zorzal is an associate professor of computer science \& engineering at Institute of Science and Technology, Federal University of Sao Paulo. He is an integrated researcher at Professional Master in Technological Innovation. He is simultaneously an associate researcher of the Visualisation and Intelligent Multimodal Interfaces Group at INESC-ID, IST, University of Lisbon, Portugal. His main research interests are virtual reality, augmented reality, educational and medical user interfaces.

\section{References}

Abhari, K., Baxter, J. S., Chen, E. C., Khan, A. R., Peters, T. M., de Ribaupierre, S., and Eagleson, R. (2014). Training for planning tumour resection: augmented reality and human factors. IEEE Transactions on Biomedical Engineering, 62(6):1466-1477.

Aebersold, M., Voepel-Lewis, T., Cherara, L., Weber, M., Khouri, C., Levine, R., and Tait, A. R. (2018). Interactive anatomy-augmented virtual simulation training. Clinical simulation in nursing, 15:34-41.

Aziz, F. A., Alsaeed, A. S., Sulaiman, S., Ariffin, M. K. A. M., and Al-Hakim, M. F. (2020). Mixed reality improves education and training in assembly processes. Journal of Engineering \& Technological Sciences, 52(4).

Bacca, J., Baldiris, S., Fabregat, R., and Kinshuk (2018). Insights into the factors influencing student motivation in Augmented Reality learning experiences in Vocational Education and Training. Frontiers in Psychology, 9(AUG).

Balian, S., McGovern, S. K., Abella, B. S., Blewer, A. L., and Leary, M. (2019). Feasibility of an augmented reality cardiopulmonary resuscitation training system for health care providers. Heliyon, 5(8):e02205.

Barata, G., Gama, S., Jorge, J., and Gonçalves, D. (2013). So fun it hurts - gamifying an engineering course. In Schmorrow, D. D. and Fidopiastis, C. M., editors, Foundations of Augmented Cognition, pages 639-648, Berlin, Heidelberg. Springer Berlin Heidelberg.

Barsom, E., Graafland, M., and Schijven, M. (2016). Systematic review on the effectiveness of augmented reality applications in medical training. Surgical endoscopy, 30(10):4174-4183.

Bifulco, P., Narducci, F., Vertucci, R., Ambruosi, P., Cesarelli, M., and Romano, M. (2014). Telemedicine supported by Augmented Reality: An interactive guide for untrained people in performing an ECG test. BioMedical Engineering Online, 13(1):1-16.

Blanco-Novoa, Ó., Fernández-Caramés, T. M., Fraga-Lamas, P., and Vilar-Montesinos, M. (2018). A practical evaluation of commercial industrial augmented reality systems in an industry 4.0 shipyard. IEEE Access, 6:8201-8218.

Boonbrahm, P., Kaewrat, C., and Boonbrahm, S. (2019). Interactive marker-based augmented reality for CPR training. International Journal of Technology, 10(7):1326.

Borsci, S., Lawson, G., and Broome, S. (2015). Empirical evidence, evaluation criteria and challenges for the effectiveness of virtual and mixed reality tools for training operators of car service maintenance. Computers in Industry, 67:17-26.

Burger, N., Demartini, M., Tonelli, F., Bodendorf, F., and Testa, C. (2017). Investigating Flexibility as a Performance Dimension of a Manufacturing Value Modeling Methodology (MVMM): A Framework for Identifying Flexibility Types in Manufacturing Systems. Procedia CIRP, 63:33-38.

Büttner, S., Prilla, M., and Röcker, C. (2020). Augmented reality training for industrial 
assembly work-are projection-based ar assistive systems an appropriate tool for assembly training? In Proceedings of the 2020 CHI Conference on Human Factors in Computing Systems, pages 1-12.

Catal, C., Akbulut, A., Tunali, B., Ulug, E., and Ozturk, E. (2019). Evaluation of augmented reality technology for the design of an evacuation training game. Virtual Reality, pages $1-10$.

Damiani, L., Demartini, M., Guizzi, G., Revetria, R., and Tonelli, F. (2018). Augmented and virtual reality applications in industrial systems: A qualitative review towards the industry 4.0 era. IFAC-PapersOnLine, 51(11):624-630.

Damiani, L., Revetria, R., and Volpe, A. (2015). Augmented reality and simulation over distributed platforms to support workers. In Proceedings of the 2015 Winter Simulation Conference, WSC '15, pages 3214-3215, Piscataway, NJ, USA. IEEE Press.

Davies, R. (2015). Industry 4.0. Digitalisation for productivity and growth. European Parliamentary Research Service, (September):10.

de Souza Cardoso, L. F., Mariano, F. C. M. Q., and Zorzal, E. R. (2020). A survey of industrial augmented reality. Computers $\&$ Industrial Engineering, 139:106159.

Demartini, M., Tonelli, F., Damiani, L., Revetria, R., and Cassettari, L. (2017). Digitalization of manufacturing execution systems: The core technology for realizing future smart factories. 22nd Summer School "Francesco Turco" - Industrial Systems Engineering 2017, 2017-Septe:326-333.

Doshi, A., Smith, R. T., Thomas, B. H., and Bouras, C. (2017a). Use of projector based augmented reality to improve manual spot-welding precision and accuracy for automotive manufacturing. The International Journal of Advanced Manufacturing Technology, 89(58):1279-1293.

Doshi, A., Smith, R. T., Thomas, B. H., and Bouras, C. (2017b). Use of projector based augmented reality to improve manual spot-welding precision and accuracy for automotive manufacturing. International Journal of Advanced Manufacturing Technology, 89(5-8):12791293.

Eder, M., Hulla, M., Mast, F., and Ramsauer, C. (2020). On the application of augmented reality in a learning factory working environment. Procedia Manufacturing, 45:7-12.

Ferrati, F., Erkoyuncu, J. A., and Court, S. (2019). Developing an augmented reality based training demonstrator for manufacturing cherry pickers. Procedia CIRP, 81:803-808.

Gabajová, G., Furmannová, B., Medvecká, I., Grznár, P., Krajčovič, M., and Furmann, R. (2019). Virtual training application by use of augmented and virtual reality under university technology enhanced learning in slovakia. Sustainability, 11(23):6677.

Habig, S. (2019). Who can benefit from augmented reality in chemistry? sex differences in solving stereochemistry problems using augmented reality. British Journal of Educational Technology, 52:629-644.

Herron, J. (2016). Augmented Reality in Medical Education and Training. Journal of Electronic Resources in Medical Libraries, 13(2):51-55.

Hořejší, P. (2015). Augmented reality system for virtual training of parts assembly. Procedia Engineering, 100:699-706.

Hou, L., Chi, H.-L., Tarng, W., Chai, J., Panuwatwanich, K., and Wang, X. (2017). A framework of innovative learning for skill development in complex operational tasks. Automation in Construction, 83:29-40.

Jacobs, R. L. and Osman-Gani, A. A. (1999). Status, impacts and implementation issues of structured on-the-job training: a study of singapore-based companies. Human Resource Development International, 2:17-24.

Jetter, J., Eimecke, J., and Rese, A. (2018). Augmented reality tools for industrial applications: What are potential key performance indicators and who benefits? Computers in Human Behavior, 87:18-33.

Kitchenham, B. and Charters, S. (2007). Guidelines for performing systematic literature reviews in software engineering.

Kobayashi, L., Zhang, X., Collins, S., Karim, N., and Merck, D. (2018). Exploratory Appli- 
cation of Augmented Reality/Mixed Reality Devices for Acute Care Procedure Training. Western Journal of Emergency Medicine, pages 158-164.

Koo, G., Lee, N., and Kwon, O. (2019). Combining object detection and causality mining for efficient development of augmented reality-based on-the-job training systems in hotel management. New Review of Hypermedia and Multimedia, 25(3):112-136.

Koutitas, G., Smith, S., and Lawrence, G. (2020). Performance evaluation of ar/vr training technologies for ems first responders. VIRTUAL REALITY.

Kwon, C. and Kim, D. H. (2019). A comparative study on the effectiveness of the training system of an augmented reality-based automated external defibrillator with an added tactile sense. International Journal of Innovative Technology and Exploring Engineering, 8.

Lee, I. J. (2019). Using augmented reality to train students to visualize three-dimensional drawings of mortise-tenon joints in furniture carpentry. Interactive Learning Environments, $0(0): 1-15$.

Leitritz, M. A., Ziemssen, F., Suesskind, D., Partsch, M., Voykov, B., Bartz-Schmidt, K. U., and Szurman, G. B. (2014). Critical evaluation of the usability of augmented reality ophthalmoscopy for the training of inexperienced examiners. Retina, 34(4):785-791.

Li, X., Yi, W., Chi, H. L., Wang, X., and Chan, A. P. (2018). A critical review of virtual and augmented reality (VR/AR) applications in construction safety. Automation in Construction, 86(November 2017):150-162.

Liberati, A., Altman, D. G., Tetzlaff, J., Mulrow, C., Gøtzsche, P. C., Ioannidis, J. P. A., Clarke, M., Devereaux, P. J., Kleijnen, J., and Moher, D. (2009). The prisma statement for reporting systematic reviews and meta-analyses of studies that evaluate health care interventions: Explanation and elaboration. PLoS Medicine, 6(7):e1000100.

Limbu, B. H., Jarodzka, H., Klemke, R., Wild, F., and Specht, M. (2018). From ar to expertise: A user study of an augmented reality training to support expertise development. Journal of Universal Computer Science, 24(2):108-128.

Longo, F., Nicoletti, L., and Padovano, A. (2017). Smart operators in industry 4.0: A humancentered approach to enhance operators' capabilities and competencies within the new smart factory context. Computers $\mathcal{E}$ industrial engineering, 113:144-159.

Martino, S., Gonbeau, O., Boisseau, C., Recapet, J.-P., Blanc, F., and Augustin, B. (2017). Enedis field experience of augmented and virtual-reality technologies at the service of network operators. CIRED-Open Access Proceedings Journal, 2017(1):1081-1084.

Mendoza, M., Mendoza, M., Mendoza, E., and González, E. (2015). Augmented reality as a tool of training for data collection on torque auditing. Procedia Computer Science, 75:5-11.

Mitsuhara, H., Iguchi, K., and Shishibori, M. (2017). Using digital game, augmented reality, and head mounted displays for immediate-action commander training. International Journal of Emerging Technologies in Learning, 12(2).

Moher, D., Liberati, A., Tetzlaff, J., and Altman, D. G. (2010). Preferred reporting items for systematic reviews and meta-analyses: The prisma statement. International Journal of Surgery, 8(5):336-341.

Mourtzis, D., Zogopoulos, V., and Vlachou, E. (2018). Augmented reality supported product design towards industry 4.0: A teaching factory paradigm. Procedia Manufacturing, 23:207212.

Okazaki, T. and Takaseki, R. (2017). Override ship maneuvering simulator using ar toolkit. Intelligent Automation \&3 Soft Computing, 23(1):167-174.

Pena-Rios, A., Hagras, H., Owusu, G., and Gardner, M. (2018). Furthering service 4.0: Harnessing intelligent immersive environments and systems. IEEE Systems, Man, and Cybernetics Magazine, 4(1):20-31.

Perdikakis, A., Araya, A., and Kiritsis, D. (2015). Introducing augmented reality in next generation industrial learning tools: a case study on electric and hybrid vehicles. Procedia engineering, 132:251-258.

Pfeiffer, T. and Renner, P. (2014). Eyesee3d: a low-cost approach for analysing mobile 3d eye tracking data using augmented reality technology. In Proceedings of the Symposium on Eye Tracking Research and Applications. 
Piedimonte, P. and Ullo, S. L. (2018). Applicability of the mixed reality to maintenance and training processes of c4i systems in italian air force. In 2018 5th IEEE International Workshop on Metrology for AeroSpace (MetroAeroSpace), pages 559-564. IEEE.

Pilati, F., Faccio, M., Gamberi, M., and Regattieri, A. (2020). Learning manual assembly through real-time motion capture for operator training with augmented reality. Procedia Manufacturing, 45:189-195.

Pinto, F., Buaes, A., Francio, D., Binotto, A. P. D., and Santos, P. (2008). Bratrack: a low-cost marker-based optical stereo tracking system. In SIGGRAPH Posters, page 131.

Quandt, M., Knoke, B., Gorldt, C., Freitag, M., and Thoben, K.-D. (2018). General requirements for industrial augmented reality applications. Procedia CIRP, 72(1):1130-1135.

Ramírez, H., Mendoza, E., Mendoza, M., and González, E. (2015). Application of augmented reality in statistical process control, to increment the productivity in manufacture. Procedia Computer Science, 75:213-220.

Rentroia-Bonito, M., Tribolet, J., Jorge, J., and Ghaoui, C. (2005). Just-in-time approach to learning: Arguing the case for cost-effective knowledge dissemination. In Ghaoui, C., Jain, M., Bannore, V., and Jain, C., editors, Knowledge-Based Virtual Education, volume 178 of Studies in Fuzziness and Soft Computing. Springer.

Rochlen, L. R., Levine, R., and Tait, A. R. (2017). First person point of view augmented reality for central line insertion training: A usability and feasibility study. Simulation in healthcare: journal of the Society for Simulation in Healthcare, 12(1):57.

Rogado, A. B. G., Quintana, A. M. V., and Mayo, L. L. (2017). Evaluation of the use of technology to improve safety in the teaching laboratory. IEEE Revista Iberoamericana de Tecnologias del Aprendizaje, 12(1):17-23.

Romero, J. A., Quero, W. D., Sánchez, J. S., and Andaluz, V. H. (2019). Training assistant for industrial processes through augmented reality. In Proceedings of the 2019 11th International Conference on Education Technology and Computers, pages 308-315.

Schmalstieg, D., Langlotz, T., and Billinghurst, M. (2011). Augmented reality 2.0. In Virtual realities, pages $13-37$. Springer.

Sebillo, M., Vitiello, G., Paolino, L., and Ginige, A. (2016). Training emergency responders through augmented reality mobile interfaces. Multimedia Tools and Applications, 75(16):9609-9622.

Segovia, D., Ramírez, H., Mendoza, M., Mendoza, M., Mendoza, E., and González, E. (2015). Machining and dimensional validation training using augmented reality for a lean process. Procedia Computer Science, 75:195-204.

Sorkoa, S. R. and Brunnhofera, M. (2019). Potentials of augmented reality in training. Procedia Manufacturing, 31:85-90.

Stefan, P., Habert, S., Winkler, A., Lazarovici, M., Fürmetz, J., Eck, U., and Navab, N. (2018). A radiation-free mixed-reality training environment and assessment concept for C-arm-based surgery. International Journal of Computer Assisted Radiology and Surgery, 13(9):1335-1344.

Stone, R. J., Guest, R., Mahoney, P., Lamb, D., and Gibson, C. (2017). A 'mixed reality' simulator concept for future medical emergency response team training. Journal of the Royal Army Medical Corps, 163(4):280-287.

Syberfeldt, A., Danielsson, O., Holm, M., and Wang, L. (2016). Dynamic operator instructions based on augmented reality and rule-based expert systems. Procedia CIRP, 41:346-351.

Tamaazousti, M., Naudet-Collette, S., Gay-Bellile, V., Bourgeois, S., Besbes, B., and Dhome, M. (2016). The constrained SLAM framework for non-instrumented augmented reality: Application to industrial training. Multimedia Tools and Applications, 75(16):9511-9547.

Tatić, D. and Tešić, B. (2017). The application of augmented reality technologies for the improvement of occupational safety in an industrial environment. Computers in Industry, $85: 1-10$.

Tenório, T., Bittencourt, I. I., Isotani, S., and Silva, A. P. (2016). Does peer assessment in on-line learning environments work? a systematic review of the literature. Computers in Human Behavior, 64:94-107. 
Torres-Jiménez, E., Rus-Casas, C., Dorado, R., and Jiménez-Torres, M. (2018). Experiences using qr codes for improving the teaching-learning process in industrial engineering subjects. IEEE Revista Iberoamericana de Tecnologias del Aprendizaje, 13(2):56-62.

Ullo, S. L., Piedimonte, P., Leccese, F., and De Francesco, E. (2019). A step toward the standardization of maintenance and training services in C4I military systems with Mixed Reality application. Measurement: Journal of the International Measurement Confederation, 138:149-156.

Uva, A. E., Gattullo, M., Manghisi, V. M., Spagnulo, D., Cascella, G. L., and Fiorentino, M. (2018). Evaluating the effectiveness of spatial augmented reality in smart manufacturing: a solution for manual working stations. International Journal of Advanced Manufacturing Technology, 94(1-4):509-521.

van Lopik, K., Sinclair, M., Sharpe, R., Conway, P., and West, A. (2020). Developing augmented reality capabilities for industry 4.0 small enterprises: Lessons learnt from a content authoring case study. Computers in Industry, 117:103208.

Wanderley, I., Kelner, J., Costa, N., and Teichrieb, V. (2006). A survey of interaction in mixed reality systems. In Symposium on Virtual Reality, pages 1-4.

Wang, M., Callaghan, V., Bernhardt, J., White, K., and Peña-Rios, A. (2018). Augmented reality in education and training: pedagogical approaches and illustrative case studies. Journal of Ambient Intelligence and Humanized Computing, 9(5):1391-1402.

Wang, Y., Anne, A., and Ropp, T. (2016). Applying the Technology Acceptance Model to Understand Aviation Students' Perceptions toward Augmented Reality Maintenance Training Instruction. International Journal of Aviation, Aeronautics, and Aerospace, 3(4).

Wang, Z., Bai, X., Zhang, S., He, W., Zhang, X., Yan, Y., and Han, D. (2020). Information-level real-time ar instruction: a novel dynamic assembly guidance information representation assisting human cognition. The International Journal of Advanced Manufacturing Technology, pages $1-19$.

Westerfield, G., Mitrovic, A., and Billinghurst, M. (2015). Intelligent augmented reality training for motherboard assembly. International Journal of Artificial Intelligence in Education, 25(1):157-172.

Wright, T., de Ribaupierre, S., and Eagleson, R. (2017). Design and evaluation of an augmented reality simulator using leap motion. Healthcare technology letters, 4(5):210-215.

Yang, C.-K., Chen, Y.-H., Chuang, T.-J., Shankhwar, K., and Smith, S. (2019). An augmented reality-based training system with a natural user interface for manual milling operations. Virtual Reality, pages 1-13.

Yew, A. W., Ong, S. K., and Nee, A. Y. (2016). Towards a griddable distributed manufacturing system with augmented reality interfaces. Robotics and Computer-Integrated Manufacturing, 39:43-55.

Zhou, J., Lee, I., Thomas, B., Menassa, R., Farrant, A., and Sansome, A. (2015). In-Situ Support for Automotive Manufacturing Using Spatial Augmented Reality. International Journal of Virtual Reality, 11(1):33-41. 